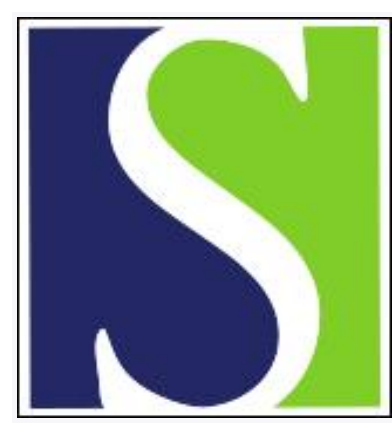

Scand J Work Environ Health 1991;17(5):356-359

https://doi.org/10.5271/sjweh.1692

Issue date: Oct 1991

Cancer incidence among pulp and paper workers exposed to organic chlorinated compounds formed during chlorine pulp bleaching.

by Jappinen $P$, Pukkala $E$

Affiliation: Enso-Gutzeit Oy, Occupational Health Centre, Imatra, Finland.

This article in PubMed: www.ncbi.nlm.nih.gov/pubmed/1947921

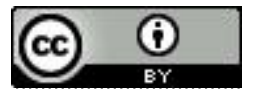




\title{
Cancer incidence among pulp and paper workers exposed to organic chlorinated compounds formed during chlorine pulp bleaching
}

\author{
by Paavo Jäppinen, $M D,{ }^{1}$ Eero Pukkala, $M A^{2}$
}

\begin{abstract}
JÄPPINEN P, PUKKALA E. Cancer incidence among pulp and paper workers exposed to organic chlorinated compounds formed during chlorine pulp bleaching. Scand J Work Environ Health 1991;17:356-9. The risk of cancer of 152 male workers exposed to organic chlorine compounds formed during chlorine pulp bleaching was assessed in a retrospective cohort study. The men had worked continuously for at least one year in selected job categories between 1 January 1945 and 31 December 1961. The cohort was followed for death and cancer incidence until 31 December 1987 with the use of the data of the National Population Register and the Finnish Cancer Registry. There were 12 observed cancers against 8.1 expected [standardized incidence ratio (SIR) 1.5, $95 \%$ confidence interval $(95 \%$ CI) $0.8-2.6$ ]. Among the stock preparation workers $(\mathrm{N}=53$ ), a significantly elevated risk of lung cancer was found ( 6 observed, 1.0 expected, SIR $6.3,95 \%$ CI $2.3-14$ ) that was especially prominent after a latency (time since first employment) of at least 15 years and in the age group of 35 to 59 years. Although all of the cases involved smokers, a part of the increased incidence may be associated with the workplace exposure to organic chlorinated compounds.
\end{abstract}

Key terms: cohort study, dioxin, lung cancer.

Numerous chlorinated organic compounds are formed during the chlorine bleaching of wood pulp (1-4), and they have been found both in bleached pulpmill effluents and in end products. Among them are polychlorinated dibenzodioxins (PCDD) and polychlorinated dibenzofurans (PCDF). Many of these chlorinated compounds are toxic, mutagenic, teratogenic, and also carcinogenic in experimental animals. One of the major PCDD compounds formed during chlorine pulp bleaching and found in many paper products, $2,3,7,8$-tetrachlordibenzodioxin, is the most potent animal carcinogen that has been tested (5).

Recently, many volatile organohalogen compounds with a low molecular weight have been identified in liquors from different bleaching stages (6) and also in workplace air of the bleaching departments (Rosenberg et al, unpublished data). It is also possible that PCDD and PCDF can spread from washing drums of the bleaching department to workplace air with water vapor.

There are some reports of an increased cancer risk among pulp and paper workers. Among the cancers with a reported increased risk are lymphomas (7-9), leukemias $(8-10)$, gastrointestinal cancers $(7-11)$, oral and pharyngeal cancers $(9,12,13)$, and lung cancer $(9,13-16)$. A significant excess of lung cancer was reported for male board-mill workers in a Finnish study (16) [40 observed, 18.1 expected, standardized incidence ratio (SIR) 222, $95 \%$ confidence interval

\footnotetext{
1 Enso-Gutzeit Oy, Occupational Health Centre, Imatra, Finland.

${ }^{2}$ Finnish Cancer Registry, Helsinki, Finland.

Reprint requests to: Dr $P$ Jäppinen, Enso-Gutzeit Oy, Occupational Health Centre, SF-55800 Imatra, Finland.
}

(95\% CI) 158-302], and the risk increased as the latency since first employment and the duration of employment increased.

Since pulp and paper workers are exposed to potentially carcinogenic compounds formed during chlorine pulp bleaching, a study was performed to assess the cancer risk of workers undoubtedly exposed to these compounds in the bleaching and board manufacturing departments of a large pulp and paper mill.

\section{Subjects and methods}

The study population consisted of 152 male workers in a large pulp and paper mill in the province of Kymi in southeastern Finland with the following job categories: bleaching plant operators, stock preparation workers, board machine workers, and slitter-rewinder operators (table 1). They were all included in the original cohort of a previously reported Finnish study (16) in which a significantly increased risk of lung cancer was found among pulp and paper workers in general, and especially among board mill workers. In addition to a longer follow-up time than in the original study, the job categories in this study were chosen so that the workers were exposed to chlorinated organic compounds via either the respiratory system or the skin. In the bleaching department and, especially, the stock preparation department, with partially open vats, the workers were exposed to vapors, spent liquor, and pulp splashes. At the board machines the workers were exposed to process water and pulp splashes and to a smaller amount of board dust. The latter was the main source of exposure at the slitter-rewinders.

A worker was included in the cohort if he had worked continuously in his job for at least one year 
between 1 January 1945 and 31 December 1961. Therefore, the shortest latency time since first employment was one year, and the calculation of the person-years and cancer cases started one year after the first employment. The cohort was followed for incident cancers from 1 January 1953 until 31 December 1987 with the use of the data of the Finnish Cancer Registry. The registry has virtually complete data on all primary cancers notified in Finland since 1953.

The person-years ( 4095 for the whole cohort) (table 1) were calculated until death (according to the data of the National Population Register) or the general closing date (31 December 1987), whichever came first. The expected numbers of primary cancers were calculated for three calendar periods (1953 - 1965, 19661976, and 1977-1987) and for four follow-up times ( $1-4$ years, $5-9$ years, $10-14$ years, and $\leq 15$ years) since first employment and for three age groups ( $\leq 29$ years, $30-59$ years, and $\geq 60$ years). We estimated the expected numbers of cases by multiplying the age- and calendar-period specific numbers of person-years at risk with the corresponding cancer incidence rates of the local central hospital district with a population of approximately 135000 . There were small differences in the age-standardized cancer incidence rates between the whole country and the local central hospital district, with site-specific variations. For instance, the incidence rate for all primary cancers among the men in the whole country was 267.1 per 100000 inhabitants during 1977 to 1987 , while the corresponding rate in the local hospital district was 242.4. For lung cancer, the corresponding figures were 69.5 and 62.7 , respectively. SIR values were obtained as ratios between the observed and expected numbers of cases. The $95 \%$ CI values were estimated on the assumption of a Poisson distribution for the observed numbers of cases.

\section{Results}

There were 12 cancers against 8.1 expected in the whole study population (SIR 1.5, $95 \%$ CI 0.8-2.6) (table 2), 11 of which occurred after a latency of at least 15 years (6.4 expected). Seven of the 12 primary cancers were in the age group 30-59 years (4.7 expected), and five occurred in the group of $\geq 60$ years ( 3.3 expected).
There were seven lung cancers against 2.3 expected (SIR 3.0, $95 \%$ CI 1.2-6.2), two cancers of the digestive organs against 2.1 expected (one stomach and one pancreas cancer), one cancer of the genital organs, one bladder cancer, and one brain cancer.

Among the bleaching plant operators, two cancers had been diagnosed against 1.1 expected, one pancreas and one brain cancer. Both workers had started to work in the bleaching plant in 1955, and both cases were diagnosed when the worker was over 60 years of age, in 1982 and 1987.

Among the stock preparation workers, there were nine cancers against 3.1 expected (SIR 2.9, $95 \% \mathrm{CI}$ 1.3-5.4) (table 3). Six of them were lung cancers (1.0 expected, SIR 6.3, $95 \%$ CI 2.3-14). Five of the lung cancers occurred after a latency of at least 15 years ( 0.8 expected). The risk was the most prominent in the age group of $30-59$ years ( 4 observed, 0.5 expected, SIR 7.8, $95 \%$ CI 2.1-20). According to the records of the company health unit, all lung cancer patients among the stock preparation workers were smokers. In addition to the lung cancers, there was one stomach cancer, one cancer of the genital organs, and one bladder cancer among the stock preparation workers.

Among the board machine and slitter-rewinder workers there was one cancer against 3.9 expected (SIR $0.3,95 \%$ CI $0.01-1.4)$. The only cancer was a lung cancer that occurred after a latency of at least 15 years.

\section{Discussion}

Only 152 subjects were included in this study. It was not possible to form a larger cohort with definite exposure to organic chlorinated compounds formed during pulp bleaching. Subjects with other job categories

Table 1. Study population and person-years by job category.

\begin{tabular}{|c|c|c|}
\hline Job category & $\begin{array}{c}\text { Number of } \\
\text { workers }\end{array}$ & Person-years \\
\hline Bleaching plant operators & 13 & 377 \\
\hline Stock preparation workers & 53 & 1395 \\
\hline $\begin{array}{l}\text { Board machine and slitter- } \\
\text { rewinder workers }\end{array}$ & 86 & 2323 \\
\hline Total & 152 & 4095 \\
\hline
\end{tabular}

Table 2. The observed $(O)$ numbers of all primary cancers and lung cancer among the men exposed to organic chlorinated compounds in the bleaching and stock preparation departments, at the board machines and slitter-rewinders, and the corresponding standardized incidence ratios (SIR) with $95 \%$ confidence intervals ( $95 \% \mathrm{CI}$ ), by latency (time since first employment). The incidence rates of the local central hospital district have been used as reference.

\begin{tabular}{|c|c|c|c|c|c|c|c|c|c|c|c|c|}
\hline \multirow{3}{*}{ Site $^{a}$} & \multicolumn{12}{|c|}{ Latency } \\
\hline & \multicolumn{3}{|c|}{$1-4$ years } & \multicolumn{3}{|c|}{$5-14$ years } & \multicolumn{3}{|c|}{$\geq 15$ years } & \multicolumn{3}{|c|}{ Total } \\
\hline & 0 & SIR & $95 \% \mathrm{Cl}$ & 0 & SIR & $95 \% \mathrm{Cl}$ & 0 & SIR & $95 \% \mathrm{Cl}$ & 0 & SIR & $95 \% \mathrm{Cl}$ \\
\hline All cancers $(140-209)$ & 1 & 3.6 & $0.1-20$ & - & - & $0-11$ & 11 & 1.7 & $0.9-3.1$ & 12 & 1.5 & $0.8-2.6$ \\
\hline $\begin{array}{l}\text { Trachea, bronchi, and } \\
\text { lungs (162) }\end{array}$ & 1 & 27 & $0.7-151$ & - & - & $0-56$ & 6 & 3.0 & $1.1-6.6$ & 7 & 3.0 & $1.2-6.2$ \\
\hline
\end{tabular}

a Code of the International Classification of Diseases, eighth revision, in parentheses. 
Table 3. The observed $(O)$ numbers of all primary cancers and lung cancer among the men exposed to organic chlorinated compounds in the stock preparation and the corresponding standardized incidence ratios (SIR) with $95 \%$ confidence intervals $(95 \% \mathrm{Cl})$, by latency (time since first employment). The incidence rates of the local central hospital district have been used as reference.

\begin{tabular}{|c|c|c|c|c|c|c|c|c|c|c|c|c|}
\hline \multirow{3}{*}{ Site $^{a}$} & \multicolumn{12}{|c|}{ Latency } \\
\hline & \multicolumn{3}{|c|}{$1-4$ years } & \multicolumn{3}{|c|}{$5-14$ years } & \multicolumn{3}{|c|}{$\geq 15$ years } & \multicolumn{3}{|c|}{ Total } \\
\hline & 0 & SIR & $95 \% \mathrm{Cl}$ & 0 & SIR & $95 \% \mathrm{Cl}$ & 0 & SIR & $95 \% \mathrm{Cl}$ & 0 & SIR & $95 \% \mathrm{Cl}$ \\
\hline All cancers $(140-209)$ & 1 & 8.6 & $0.2-48$ & - & - & $0-26$ & 8 & 3.3 & $1.4-6.6$ & 9 & 2.9 & $1.3-5.4$ \\
\hline $\begin{array}{l}\text { Trachea, bronchi, and } \\
\text { lungs (162) }\end{array}$ & 1 & 60 & $1.5-336$ & - & - & $0-115$ & 5 & 6.4 & $2.1-15$ & 6 & 6.3 & $2.3-14$ \\
\hline
\end{tabular}

a Code of the International Classification of Diseases, eighth revision, in parentheses.

within the pulp and board mills had not been exposed to a great extent to organic chlorinated compounds, but otherwise had a rather variable exposure pattern. Even the workers in this study had been exposed to a variety of chemicals. Especially those working at the board machines had been exposed, for example, to dyes, optical brighteners, slime controlling and coating agents, maintenance chemicals, and also asbestos. The average follow-up time of $>25$ years produced more than 4000 person-years and made it however possible to draw some conclusions from the cancer incidence of workers with definite long-term exposure to chlorinated compounds.

The number of all cancers combined was slightly more than expected, which is not a common finding among industrial populations. The excess was due to lung cancer among the stock preparation workers.

All of the stock preparation workers with lung cancer were smokers, but there are no data about the amount of tobacco consumption. Pukkala et al (17) have reported a close positive correlation between the SIR of lung cancer and the occupational categoryspecific prevalence of smoking in Finland, but Axelson (18) has, on the other hand, postulated that only rarely does the confounding effect of smoking distort the risk ratios of lung cancer outside the range of $0.5-1.5$ in industrial populations. The lower $95 \%$ confidence limit of the SIR found in our study was 2.3. Therefore, it is probable that smoking alone does not explain the excess risk of lung cancer found.

Stock preparation workers are the first subjects along the paper and board manufacturing process to be exposed to compounds formed during chlorine pulp bleaching. The excess risk for lung cancer was the most prominent after a latency of at least 15 years and at the age of 35-59 years, which is not the typical age for smoking-related lung cancers. Our conclusion on the basis of this small cohort study is that the increased risk of lung cancer found among stock preparation workers may be connected with workplace exposure to organic chlorinated compounds formed during chlorine pulp bleaching.

\section{References}

1. Kringstad KP, Lindström K. Spent liquors from pulp bleaching. Environ Sci Technol 1984; 18:236-48.

2. De Sousa F, Kolar M-C, Kringstad KP, Swanson SE, Rappe C, Glas B. Influence of chlorine ratio and oxygen bleaching on the formation of PCDFs and PCDDs in pulp bleaching: part 1 . a laboratory study. Tappi $\mathrm{J}$ 1989;72:147-53.

3. Rappe C. Environmental stable chlorinated contaminants from the pulp and paper industry. In: Vainio $\mathrm{H}$, Sorsa M, McMichael AJ, ed. Complex mixtures and cancer risk. Lyon: International Agency for Research on Cancer, 1990. (IARC scientific publications; no 104.)

4. Suntio RL, Ying Shiu W, Mackay D. A review of the nature and properties of chemicals present in pulp mill effluents. Chemosphere 1988;17:1249-90.

5. Vainio $H$, Hesso A, Jäppinen $P$. Chlorinated dioxins and dibenzofurans in the environment - a hazard to public health? Scand J Work Environ Health 1989;15: 377-82.

6. Rosenberg C, Aalto T, Tornaeus J, Hesso J, Jäppinen $P$, Vainio $H$. Volatile organohalogen compounds formed during bleaching of kraft pulp - identification by capillary chromatography mass spectrometry. J Chromatogr (in press).

7. Robinson CF, Waxweiler RJ, Fowler DP. Mortality among production workers in pulp and paper mills. Scand J Work Environ Health 1986;12:552-60.

8. Schwartz E. A proportionate mortality ratio analysis of pulp and paper workers in New Hampshire. $\mathrm{Br} \mathrm{J}$ Ind Med 1988;45:234-8.

9. Solet D, Zoloth SR, Sullivan C, Jewett J, Michaels DM. Patterns of mortality in pulp and paper workers. J Occup Med 1989;31:627-30.

10. Henneberger PK, Ferris BG Jr, Monson RR. Mortality among pulp and paper workers in Berlin, New Hampshire. Br J Ind Med 1989;46:658-64.

11. Milham $S \mathrm{~J}_{r}$, Hesser JE. Hodgkin's disease in woodworkers. Lancet 1967;2:136-7.

12. Decouflé P, Stanislawczyk K, Houten L, Bross IDJ, Viadana $\mathrm{E}$. A retrospective survey of cancer in relation to occupation. Washington, DC: US Government Printing Office, 1977. (DHEW (NIOSH) publication; no $77-178$ ).

13. Menck HR, Henderson BE. Occupational differences in rates of lung cancer. J Occup Med 1976;18:797-801.

14. Harrington JM, Blot WJ, Hoover RN, Housworth WJ, Heath CW, Fraumeni JF Jr. Lung cancer in coastal Georgia: a death certificate analysis of occupation. J Natl Cancer Inst 1978;60:295-8.

15. Nurminen $M$, Hernberg S. Cancer mortality among carbon disulfide-exposed workers [Letter to the editor]. $J$ 
Occup Med 1984;26:341.

16. Jäppinen P, Hakulinen T, Pukkala E, Tola S, Kurppa $K$. Cancer incidence of workers in the Finnish pulp and paper industry. Scand J Work Environ Health 1987;13: 197-202.

17. Pukkala E, Teppo L, Hakulinen T, Rimpelä M. Occupation and smoking as risk determinants of lung can- cer. Int J Epidemiol 1983;12:290-6

18. Axelson $O$. Aspects on confounding in occupational health epidemiology [Letter to the editor]. Scand J Work Environ Health 1978;4:98-102.

Received for publication: 24 January 1991 